\title{
RESUMO
}

\section{SEPARAÇÃO OBRIGATÓRIA DE BENS NAS RELAÇÕES SEPTUAGENÁRIAS: PROTEÇÃO OU DISCRIMINAÇÃO?}

\section{MANDATORY SEPARATION OF PROPERTY IN SEPTUAGENARY RELATIONS: PROTECTION OR DISCRIMINATION?}

\section{SEPARACIÓN OBLIGATORIA DE PROPIEDAD EN RELACIONES SEPTUAGENARIAS: ¿PROTECCIÓN ODISCRIMINACIÓN?}

\begin{abstract}
A legislação brasileira impõe limites patrimoniais às pessoas idosas que pretendem contrair matrimônio, ao estabelecer o regime de separação obrigatória de bens. A imposição legal do regime de bens para as pessoas maiores de setenta anos de idade é matéria controvertida na doutrina no sentido de que se essa imposição visa de fato a proteção integral da pessoa idosa ou configura mera discriminação. A matéria merece ser analisada sobre o prisma da autonomia da vontade e de outros princípios constitucionais, partindo-se de recentes estudos e decisões judiciais proferidas pelos tribunais superiores, visando analisar a atuação do sistema de justiça, e os mecanismos utilizados para efetivação de direitos.
\end{abstract}

\section{PALAVRAS-CHAVE}

Autonomia privada; Idoso; Princípios Constitucionais. 


\section{ABSTRACT}

Brazilian legislation imposes property limits on elderly people who intend to enter into marriage, by establishing the mandatory separation of property regime. The legal imposition of the property regime for people over seventy years of age is a controversial matter in the doctrine in the sense that whether this imposition is in fact aimed at the full protection of the elderly person or constitutes mere discrimination. The matter deserves to be analyzed under the prism of autonomy of will and other constitutional principles, based on recent studies and judicial decisions handed down by higher courts, aiming to analyze the performance of the justice system, and the mechanisms used to enforce rights.

\section{KEYWORDS}

Private autonomy. Elderly people. Constitutional principles.

\section{RESUMEN}

La ley brasileña impone límites patrimoniales a las personas mayores que pretenden contraer matrimonio, al establecer el régimen obligatorio de separación patrimonial. La imposición legal del régimen de propiedad para las personas mayores de setenta años es un tema controvertido en la doctrina en el sentido de que si esta imposición en realidad tiene como objetivo la protección integral de la persona mayor o constituye una mera discriminación. El asunto merece ser analizado bajo el prisma de la autonomía de la voluntad y otros principios constitucionales, a partir de estudios recientes y decisiones judiciales dictadas por los tribunales superiores, con el objetivo de analizar el desempeño de la justicia y los mecanismos utilizados para hacer valer los derechos.

\section{PALABRAS CLAVE}

Autonomía privada; Anciano; Principios constitucionales. 


\section{INTRODUÇ̄̃̃O}

Com o aumento da expectativa de vida dos brasileiros, há elevação do índice de pessoas idosas fisicamente bem e economicamente independentes, sem uma dependência direta dos seus familiares, é normal que essas pessoas mais avançadas em idade, divorciadas e viúvas, até mesmo pessoas que nunca contraíram matrimônio procurem um novo relacionamento conjugal até o seu último dia de vida ou não. Só que encontram limites decorrentes da lei, inibindo a realização de suas vontades, resultando na desistência de contrair matrimônio em decorrência da incomunicabilidade dos patrimônios de cada consorte.

Em razão dos idosos septuagenários encontrarem limites na legislação para se casar, pretende neste estudo investigar, sob o ponto de vista constitucional, a incidência da norma jurídica prevista no artigo 1641, inciso II do Código Civil de 2002, que dispõe sobre a imposição ou obrigatoriedade do regime de separação legal de bens para os maiores de 70 (setenta) anos. Nesse sentido, questiona-se: a separação obrigatória de bens para os maiores de setenta anos é uma proteção estatal ou uma mera discriminação?

O tema a ser abordado é de grande relevância no aspecto moral e social, pois se trata em garantir aos idosos o direito de escolher o regime patrimonial de bens que mais the seja adequado, independente do critério etário, deixando a idade de ser sinônimo de incapacidade. Num primeiro momento, busca-se apresentar o problema de pesquisa na prática, ou seja, como que a questão jurídica impacta na vida das pessoas. Em seguida, serão trazidos os fundamentos teóricos do trabalho, com citações de opiniões de estudiosos do tema e sua relação com a problemática definida, servindo de lastro para toda a pesquisa.

A pesquisa tem como objetivo geral o estudo da obrigatoriedade da separação legal de bens para os idosos maiores de 70 anos, a fim de responder sobre o caráter protecionista ou discriminatório do dispositivo, que tanto tem gerado discursões doutrinárias e jurisprudenciais. Especificamente, pretende apresentar a participação efetiva do idoso na sociedade brasileira; analisar os regimes de bens, além de investigar a capacidade civil dos septuagenários sob o enfoque do aumento da expectativa e qualidade de vida.

Serão levantados os posicionamentos de algumas correntes doutrinárias, tanto a favor quanto contrária à disposição legal. A corrente patrimonialista, defensores da norma, fundamentam-se na defesa e manutenção do patrimônio do idoso, bem como dos seus herdeiros. Já a corrente personalista, que interpretam sob a ótica constitucional em que todos devem ser tratados igualmente, sem distinção de qualquer natureza, sem preconceitos, entendem ser uma norma eminentemente preconceituosa ao idoso, restringindo o seu direito de liberdade de escolha. Por isso, defendem a revogação do art. 1641, inciso II do Código Civil de 2002.

Pressupondo a inconstitucionalidade do dispositivo por afastar o direito de dispor livremente dos seus bens, violar os direitos básicos constitucionais, como o da dignidade da pessoa humana, liberdade e igualdade, podemos considerar que de fato a norma deve ser revogada, devendo, portanto, ser suscetível à propositura de um projeto de lei com essa específica finalidade. 


\section{IDOSO E A AUTONOMIA DA VONTADE}

O envelhecimento populacional no Brasil tem sido apontado como um fenômeno marcante nas décadas subsequentes, ocasionando discussões sobre a preparação da sociedade para enfrentar essa nova realidade social. Outro ponto observado é a redução na quantidade de filhos, o que representa que o país deverá estar orientado também para idosos que carecem de um cuidado Estatal, no qual hoje é realizado por suas famílias.

A avançada idade sempre foi significado de sabedoria e bastante conhecimento, como por exemplo, nas regiões de indígenas onde a palavra dos anciãos é considerada como lei. Recaindo sobre eles a responsabilidade de transmitir a cultura, crenças e costumes ao seu povo e futuras gerações (ANCIÃOS, 2002). Até em países considerados como de "primeiro mundo" como o Japão, por exemplo, as palavras dos idosos raramente são refutadas, sendo consideradas de muito discernimento e indispensável para a tomada de decisões para os demais membros da família (MASC, 2013).

Já no Brasil, atualmente, na maioria das vezes o idoso tem sido usado como meio de fonte de renda para a família "parasita" concomitantemente sendo vítimas de maus tratos e violência psicológica. Segundo Santana (2019), na teoria, é na idade avançada que os pais mais precisam do zelo, carinho e cuidado dos filhos, porém o que tem se visto é a ocorrência de exploração financeira, ou seja, envethecer no Brasil ainda é um grande risco.

O processo do envelhecimento é inerente a todo o ser vivo, cujas alterações determinam mudanças estruturais fisiológicas e nas suas funções. No caso do ser humano, esse processo assume extensões que ultrapassam o biológico, pois podem também ocasionar resultados sociais e psicológicos (OKUMA, 2004). É uma fase da vida onde o indivíduo fica mais vulnerável com o envelhecer do corpo, no entanto, o envelhecimento não está atrelado com a incapacidade, mas deve ser percebido e cuidado ao se limitar a certas atividades inerentes a essa fase (MELO; MELO, 2014).

Entende-se como idoso toda pessoa com muitos anos de vida, a Organização Mundial de Saúde (OMS) descreve como idoso toda pessoa a partir dos 60 anos de idade nos países em desenvolvimento e a partir dos 65 anos nos países já desenvolvidos. Logo, o Brasil, por meio do Estatuto do Idoso, Lei n $10.741 / 2003$, instituiu no art. $1^{\circ}$ a classificação dos idosos no país, qual seja, as pessoas iguais ou superiores a 60 anos, sendo assegurado a estes todos os direitos fundamentais inerentes à pessoa humana.

Contudo, o Brasil precisa se atentar para o envelhecimento da população nacional, de acordo com dados colhidos pelo Ministério da Saúde, o Brasil em 2016 tinha a quinta maior população idosa do mundo e em 2030 é provável que esses números estejam mais elevados, contabilizando que a população idosa ultrapassará o total de crianças entre 0 e 14 anos.

Hoje, de acordo com o Instituto Brasileiro de Geografia e Estatística (IBGE), em 2018, a população Brasileira com mais de 60 anos, contabiliza números superiores à de 28 milhões de pessoas, representando $13 \%$ da população brasileira, ou seja, partindo desse pressuposto, se vê a necessidade de políticas públicas eficazes para amparar essas pessoas nos próximos anos. Por isso, para um melhor entendimento sobre o caráter protetivo ou discriminatório da norma jurídica se faz necessário em 
primeiro plano um estudo sobre o destinatário dessa norma, o septuagenário, apresentando os dados colhidos dentro da sociedade brasileira.

Já a população acima dos 70 anos representa cerca de 10 milhões de pessoas, equivalendo a 5\% da população nacional com projeções de que nos próximos quinze anos esse percentual seja de duas vezes mais. Segundo Marri (2018), demógrafa do IBGE, estima-se que a população irá parar de crescer em 2047, favorecendo o processo de envelhecimento populacional, que representa quando os grupos mais idosos ficam em uma proporção mais elevada do que os grupos mais jovens.

Com o aumento da expectativa de vida e a elevação do índice de pessoas idosas, física e economicamente independentes, é normal que essas pessoas mais velhas, divorciadas, viúvas, procurem um novo relacionamento conjugal, só que encontram limites decorrentes da lei, dificultando a realização de suas vontades e fazendo com que essas pessoas possivelmente desistam de contrair matrimônio em decorrência da incomunicabilidade do patrimônio de cada consorte.

Cabe enfatizar que o resultado do crescimento da população nessa faixa etária é consequência de vários fatores, dentre eles o aumento da expectativa de vida que em 2020 é de 76,7 anos, segundo o IBGE (2020), também da diminuição na taxa de natalidade. Diante do cenário atual, houve grande contribuição da medicina, possibilitando a criação de diversos meios contraceptivos. Não bastando os meios preventivos, a medicina avançou no combate positivo das doenças, permitindo mais anos com qualidade de vida.

Consequentemente, com o prolongamento dos dias de vida, pesquisas demonstram uma participação mais ativa dos idosos na sociedade, sejam impulsionados por ordem econômica ou emocional. Buscam diariamente a participação no mercado de trabalho como provedores do seu lar, movimentam a economia como consumidores e a cada dia se mostram como pessoas com total capacidade de constituir família.

Uma pesquisa coordenada pela Zhuo Consultoria e Giacometti Comunicação (2014), intitulada Longevidade: a perspectiva e o impacto na sociedade, afirma que $14 \%$ dos brasileiros acima de 70 anos continuam no mercado de trabalho ativamente, sendo afirmado pelos entrevistados que com o avanço da idade necessitam de se reinventarem e o trabalho possibilita que isso aconteça.

Na seara consumerista, por exemplo, conforme pesquisa realizada pelo Sebrae (2019), os idosos são responsáveis por $20 \%$ do consumo no Brasil, dentre os mais diversos seguimentos como alimentos, cuidados médicos, remédios e condições especiais para viagens para desfrutar da sua independência financeira conquistada ao longo de anos trabalhados.

\subsection{DIREITO DE ESCOLHA DO REGIME DE BENS NO DIREITO BRASILEIRO}

Entre os anos de 1789 e 1799 na França, ocorreu a Revolução Francesa, um período que marcou o fim do absolutismo no País. Além do caráter burguês, houve uma participação popular muito grande, alcançando um elevado grau de radicalismo, visto que o povo francês enfrentava uma crise precária. Consequentemente, a revolução foi um marco histórico na humanidade, dando início a um processo de universalização dos direitos sociais e das liberdades individuais a partir da Declaração dos Direitos do Homem e do Cidadão.

Nesse período de luta pela individualidade e liberdade em todos os meios, especialmente no campo contratual, deu origem ao princípio da autonomia da vontade, configurando-se na liberdade de 
pronunciar o desejo por qual forma, objeto e pessoa a ser compactuado o contrato. Após o período Revolucionário, com o aumento das indústrias e o liberalismo intensificado prejudicou toda uma coletividade de pessoas, sendo assim, a autonomia volta a ser limitada, mas agora por lei e pela função social para garantir os direitos da sociedade.

A Liberdade e a autonomia da vontade são princípios previstos na Constituição Federal de 1988 que norteiam o momento de escolha do regime patrimonial. Os regimes encontram-se previstos a partir do art. 1.639 até o 1.688 do CC/02, sendo eles: comunhão universal de bens, comunhão parcial de bens, participação final nos aquestos e o de separação convencional/legal de bens, além da possibilidade de regimes mistos, levando-se em conta o interesse motivado do casal. Nader (2016) conceituou como sendo um estatuto que conduz os interesses patrimoniais existentes a época do casamento, durante a vida em comum, cujos efeitos se notam após uma possível ruptura, além disso define o critério de administração dos bens em geral.

No Brasil, ainda sob a vigência do Código Civil (CC) de 1916 antes da Lei 6.515/1977 (Lei do divórcio), a "regra" que prevalecia era o regime de comunhão universal de bens, no qual estabelece que todo o agrupamento patrimonial dos cônjuges se comunica, tanto os bens adquiridos anteriormente, quanto durante o casamento, pois os aspectos morais e sociais da época com forte influência religiosa pregavam que uma vez contraído o matrimônio este deveria durar toda a existência física dos cônjuges. Nesse sentido, veja-se o art. 258, CC/16. "Não havendo convenção, ou sendo nula, vigorará, quanto aos bens, entre os cônjuges, o regime da comunhão universal.”

Com a entrada em vigor da Lei do divórcio, alterando o artigo 258 do Código Civil de 1916, o regime de bens que passou a prevalecer no direito brasileiro é o da comunhão parcial de bens, estabelecendo que apenas se comunicam os bens que sobrevierem onerosamente aos cônjuges na constância do casamento. Ainda vai além, no silêncio dos nubentes, ou seja, não elaboração do pacto antenupcial ou for considerado nulo/ineficaz se aplica o regime da comunhão parcial, bem como também na união estável.

0 regime de participação final nos aquestos ainda é considerado uma inovação no ordenamento jurídico brasileiro, pois ele surgiu com a vigência do Código Civil de 2002, sendo considerado por muitos doutrinadores como um regime híbrido com aspectos da separação de bens na constância do casamento, chegando bem próximo ao da comunhão parcial no momento dissolução conjugal. Sendo assim, cada cônjuge possui patrimônio próprio, podendo administrar com exclusividade e inclusive alienar se for bem móvel, podendo ainda estabelecer no pacto antenupcial que cada um aliene seus bens imóveis livremente, caso contrário necessitará da outorga uxória.

No momento da partilha dos aquestos, após o término da sociedade conjugal, será assegurado a meação dos bens adquiridos onerosamente na constância do casamento para cada um dos cônjuges. Madaleno (2018) entende como um regime confuso e de compreensão difícil pelos cônjuges, por isso é pouco adotado se comparado aos demais regimes patrimoniais.

Por fim, o atual código traz a possibilidade de dois tipos de separação total de bens: a convencional/absoluta e a legal/obrigatória. Na primeira modalidade os cônjuges optam por conveniência por meio do pacto antenupcial onde cada um poderá ter a posse, bem como a livre e exclusiva administração do seu patrimônio, podendo alienar tanto os bens móveis quanto imóveis ou gravar com ônus real (VENOSA, 2014). 
Todos esses regimes patrimoniais apresentados têm em comum o direito à liberdade e da autonomia privada, exercendo os cônjuges a livre opção de escolherem qual regime mais se enquadra na sociedade conjugal, por meio do pacto antenupcial. Corroborando com esse mesmo entendimento, Lobo (2011) ainda afirma que essa autonomia em constituir ou extinguir uma entidade familiar não deve sofrer qualquer tipo de restrição ou imposição externa da sociedade, do legislador ou de qualquer parente.

Entretanto, essa liberdade é mitigada na separação legal/obrigatória de bens com previsão legal no art. 1641 e incisos do CC:

Art. 1.641. É obrigatório o regime da separação de bens no casamento:

I - das pessoas que o contraírem com inobservância das causas suspensivas da celebração do casamento;

II - da pessoa maior de 70 (setenta) anos; (Redação dada pela Lei no 12.344, de 2010)

III - de todos os que dependerem, para casar, de suprimento judicial. (BRASIL, 2020, on-line).

Lôbo (2017, p. 305) afirma que esse regime de bens "é tipicamente um ônus: a pessoa, incluída em alguma das três hipóteses legais, escolhe entre casar ou não casar; se prefere casar, deverá suportar o ônus do regime obrigatório de bens".

Nessa segunda modalidade de separação total de bens não há necessidade de pacto antenupcial, pois a imposição decorre da lei, não havendo possibilidade de optar por outro regime. No entanto, não mais subsistindo os impedimentos dos incisos I e III do art. 1641, os cônjuges poderão alterar o regime, desde que feito um pedido devidamente motivado por ambos, resguardando o direito de terceiros, dos entes públicos e autorização judicial. Porém, quanto ao inciso II, objeto de estudo dessa monografia, só não haverá a incidência da separação legal de bens para os maiores de 70 anos se a relação conjugal vier precedida de união estável antes de atingir a faixa etária.

No entanto, é necessário mencionar que no Código Civil de 1916 não existia essa possibilidade de alteração do regime de bens do casamento, regendo-se pela regra da imutabilidade. Em razão da concepção contida no Código vigente e alteração nas relações familiares, jurisprudência e o novo diploma em si flexibilizou "as normas postas às entidades familiares, mesmo porque a Constituição Federal de 1988 amparou as novas espécies de grupos familiares".

É importante ressaltar que a liberdade dos cônjuges foi ampliada, porém não tolerou a mudança de forma arbitrária e aleatória. Mantendo-se o princípio da segurança, outorgando-lhe ao Poder Judiciário a competência para autorizar o pedido de alteração como forma de impedir abusos. A imutabilidade, em regra, tendia a proteger a mulher casada, já que em outra esfera cultural esta era considerada de menor experiência no cuidado dos patrimônios do casamento.

Com a vigência do Código, considerando a igualdade entre cônjuges previstas na Carta Magna, seria controvertido em tempos atuais, que um dos consortes, apenas pelo gênero sexual, pudesse ser considerado mais ingênuo e com menor aprendizado em relação ao seu parceiro. Por isso, sendo apurada as razões invocadas, mediante autorização judicial, pedido motivado de ambos os cônjuges, ressalvando o direito de terceiros, é admissível a alteração do regime de bens. 
A não comunicação do patrimônio até mesmo adquirido na constância do casamento, levou o Supremo Tribunal Federal no ano de 1964, a criar a súmula 377, pois, é nítido que a adoção do regime de separação obrigatória de bens, poderá gerar um enriquecimento ilícito, tendo em vista que o outro cônjuge poderá contribuir de alguma forma (não necessariamente financeiro) para o aumento patrimonial e não desfrutará em caso de morte ou dissolução da união conjugal. Sendo assim, comunicam-se os bens adquiridos na constância do casamento.

$\mathrm{O}$ código ainda permite que os cônjuges elaborem o próprio regime patrimonial, fazendo uma mesclagem dos regimes previstos em lei, por exemplo, ficando estabelecido entre o casal que os bens móveis sejam regidos pela comunhão parcial e os bens imóveis pela comunhão universal.

\subsection{A CAPACIDADE CIVIL DO SEPTUAGENÁRIO FRENTE AO CóDIGO CIVIL DE 2002 E 0 ESTATUTO DO IDOSO}

Não são poucas as pessoas a crer que a senilidade, por si só, seja causa de incapacidade civil, ou pelo fato de dispor dos seus bens ser considerado pródigo. No entanto, por mais que as enfermidades incapacitantes se apresentem mais facilmente na "velhice" e que os idosos estejam mais suscetíveis a serem acometidos por enfermidades mentais do que os mais jovens, ou a prodigalidade comprovada, a incapacidade pode ser graduada (absoluta ou relativa), devendo cada caso específico ser observado no processo de interdição devido.

A capacidade civil do indivíduo é dividida entre a capacidade de direito e a capacidade de fato, sendo que a primeira é adquirida desde o começo da vida, seja do nascituro ou após o nascimento com vida, adquirindo a personalidade jurídica, capaz de contrair direitos e obrigações na ordem social. Já a capacidade de fato, que é a aptidão para exercer livremente por si próprio os atos da vida civil se alcança com a maioridade civil aos 18 anos completos em regra, e deve perdurar até a morte do indivíduo ou que ele seja submetido à um processo de interdição, que será citado para comparecer perante o juízo no qual será entrevistado, podendo impugnar o pedido, garantindo o devido processo legal e de ampla defesa.

Uma vez alcançada a capacidade civil de fato, não contraindo posteriormente incapacidade mental, impedimentos ou causas suspensivas previstas nos art. 1.521 ao 1.523 do Código Civil, o idoso, assim como qualquer outra pessoa estará apta para constituir matrimônio. O Estatuto do Idoso, no seu art. $2^{\circ}$, expressamente declara que todos os direitos fundamentais inerentes à pessoa humana, inclusive o direito casar ou viver em união estável, sem prejuízo da proteção integral de que trata a Lei, assegurando a ele todas as oportunidades e facilidades, para preservação de sua saúde física e mental e seu aperfeiçoamento moral, intelectual, espiritual e social, em condições de liberdade e dignidade, que devem perdurar interminavelmente.

O idoso não se enquadra no rol taxativo de incapacidade dos parágrafos terceiro e quarto do Código Civil de 2002, alterado pela Lei no 13.146/2015 (Estatuto da Pessoa com Deficiência), que classificam os menores de dezesseis anos como absolutamente incapazes e os maiores de dezesseis e menores de dezoito anos, ébrios habituais, viciados em tóxicos, pródigos e aqueles que, por causa transitória ou permanente não puderem exprimir sua vontade são classificados como relativamente incapazes. Sendo o rol taxativo, logo não pode ser ampliado, devendo perdurar a regra da capacidade nos casos que não se enquadrem nessas hipóteses. 
Nessa perspectiva, a incapacidade absoluta se diferencia da incapacidade relativa, onde na primeira, os atos são nulos de pleno direito, enquanto na segunda, os atos serão anuláveis nos casos em que a parte interessada ajuizar ação judicial competente fundamentada no art. 178 do Código Civil.

A título exemplificativo, levando-se em consideração os três últimos Presidentes da República Federativa do Brasil, Jair Messias Bolsonaro (atual), com 65 anos de idade, bem como os seus antecessores, Michel Miguel Elias Temer Lulia, com 78 anos na época em que deixou o cargo, bem como Dilma Vana Rousseff, com 68 anos quando deixou o cargo, todos considerados idosos perante o Estatuto do Idoso. Se essas pessoas têm a capacidade de gerir uma nação com 211,4 milhões de pessoas aproximadamente, conforme dados do IBGE (2020), de decidir o futuro do país, será que não possuem capacidade de decidir qual será seu regime de bens do seu casamento?

Ao partir para a capacidade laborativa, a aposentadoria compulsória dos servidores públicos passou de 70 anos para 75 anos de idade, por meio da aprovação da Emenda Constitucional 88/2015, medidas como essa por parte do Estado vem atestando a capacidade dos idosos.

Já a capacidade núbil, de acordo com a Lei 13.811/2019, que alterou o art. 1.520 do Código Civil, se atinge com os 16 anos completos, vedando em qualquer caso, o casamento de pessoas que não atingiram essa idade, sendo que era permitido antes da entrada em vigor da nova lei, desde que fosse para evitar imposição ou cumprimento de pena criminal ou em caso de gravidez. Mas não basta ter os 16 anos completos, se faz também necessário a anuência dos pais para os trâmites legais do matrimônio, caso não seja autorizado pelos genitores ocorrerá o chamado suprimento judicial de consentimento.

Citado acima a idade mínima para a constituição do matrimônio, porém não existe idade máxima, desde que os nubentes estejam em plena capacidade mental. 0 que permanece é a limitação para os septuagenários, impondo o regime de separação obrigatória de bens como forma tendente a limitar essa faixa etária. A inclusão do artigo 1.641 inciso II do Código Civil de 2002, é resquício do Código de 1916, fruto da concepção patrimonialista, patriarcal e controladora da vida privada decorrente de uma evolução histórica em detrimento das relações afetivas.

O artigo 258, parágrafo único, inciso II do Código Civil de 1916, trazia em sua redação a limitação de idade de 50 anos para as mulheres e 60 anos para os homens, onde a partir dessa faixa etária estariam obrigados a contrair matrimônio sob o regime da separação obrigatória de bens. Com a entrada em vigor do Código de 2002, em sua redação original, esse limite foi alterado para a idade de 60 anos para ambos os nubentes, em decorrência do princípio da isonomia.

Mesmo com a alteração legislativa, a norma jurídica continuou sendo alvo de muitas críticas por boa parte da doutrina, a exemplo de Dias, in verbis (2008, p. 149):

[...] Até agora - e esta minha frase ecoou em todo o Brasil - nós mulheres somos idiotas a partir dos 50 anos, mas daqui para frente todos passaremos a ser imbecis aos 60 . Bela vantagem: ganhamos nós mulheres mais 10 anos de higidez mental.

Em 2010, a redação do artigo 1.1641, II, CC foi alterada pela Lei 12.344/2010 que passou a prevê a faixa etária de 70 anos para ambos os sexos, sendo justificada pelo aumento na expectativa de vida do brasileiro, comparando-se ao momento da elaboração do projeto do Código Civil de 2002. 
Ao fazer uma análise pontual sobre as legislações no ordenamento jurídico brasileiro que tratam sobre o idoso, como o Estatuto do Idoso (Lei 10.741/2003), a lei de política nacional do idoso (Lei 8.842/1994), o Decreto 5. 934/2006 que estabelece mecanismos e critérios para a reserva de vagas e desconto nas passagens, dentre os demais 700 (setecentos) atos normativos que o Senado dispõe sobre essa temática, podemos perceber que em certo momento o idoso é reconhecido como pessoa autônoma e independente para cuidar dos seus próprios interesses, na qualidade de sujeitos de direitos, enquanto que em outros dispositivos são tratados por um injustificado protecionismos exacerbado, como se fossem "objeto de proteção" e que a velhice ocasionasse invariavelmente na sua incapacidade (WAQUIM; CARVALHO, 2015).

Acontece que essa perspectiva dupla, de objeto de proteção e sujeito de direitos, ocasiona grandes dificuldades na interpretação, construção e na aplicação dos direitos e garantias previstas para os idosos. Ora ferindo a sua dignidade, ora deixando-os à própria sorte. Desta maneira, analisadas as hipóteses de incapacidades acima, dificilmente se sustenta o entendimento de que ao atingir a idade de 70 (setenta) anos a pessoa se torna automaticamente um relativamente incapaz.

\subsection{PRINCÍPIO DA PROTEÇ̃̃O INTEGRAL AO IDOSO NA CONTEMPORANEIDADE}

Com o advento da Constituição Federal de 1988, se deu a positivação do princípio da proteção integral a pessoa idosa em relação a concretude dos direitos fundamentais no ordenamento jurídico brasileiro, assegurando uma velhice amparada na dignidade. A partir daí é que a proteção ao idoso passa a ser sustentada pelos princípios da dignidade da pessoa humana e no da cidadania, sendo considerada parte integrante do grupamento de direitos que irão potencializar uma sociedade livre, justa, solidária e igualitária.

Com o envelhecimento e transformações naturais do ciclo da vida humana, independente de meio social, cor, sexo, condições econômicas, alguns tem uma qualidade de vida considerável satisfatória, com alimentação adequada, dentro do convívio social e familiar, efetivando seu direito a vida, dentre outros. Entretanto, nem sempre é como deveria ser, fugindo das condições mínimas de dignidade, sem contar dos muitos casos de abandono afetivo por parte da própria "família".

Daí, a teoria da proteção integral compreende que os direitos dos idosos são repletos de particularidades que merecem uma especial proteção estatal e por isso é indispensável a aplicação de políticas públicas que alcancem os idosos e observem as suas necessidades. Sendo assim, tal doutrina ergueu-se para ressaltar a ideia de vantagem jurídica ou prioridade, com o direcionamento de proteger grupos vulneráveis expostos aos mais diversos e dolorosos riscos.

Para Indalencio (2007, p. 66), em virtude do exposto, compreende:

A ideia de prioridade é, pois, a tradução da prevalência dos direitos dos idosos colocando-o, portanto, em situação de vantagem jurídica, necessária para o resgate da igualdade. Eis aí um dos principais desdobramentos da doutrina da proteção integral, já utilizado em relação à criança e ao adolescente. 
Para que se alcance de maneira efetiva, o título III deste Estatuto, preocupou-se em dispor as medidas de proteção aplicáveis sempre que os direitos garantidos e reconhecidos forem ameaçados e/ou violados. Sendo assim, verificada qualquer das hipóteses do art. 43, o Ministério Público, bem como o Poder Judiciário poderá determinar as medidas de proteção cabíveis. Mesmo com todo arcabouço normativo, ainda é visível a inaptidão do Estado, da sociedade e até das próprias famílias para receber essa etapa da vida, portanto, a função primordial do princípio da proteção integral ao idoso é fazer com que essa desigualdade volte a equiparar-se.

Assim sendo, a prioridade atribuída ao idoso por meio do princípio da proteção integral está diretamente associada ao princípio da isonomia, no sentido de inviabilizar desequiparações injustificadas e fortuitas. A legislação infraconstitucional não pode criar diferenças em virtude apenas da idade cronológica, entende-se que o fator biológico inerente da vida humana, não é suficiente para retirar do indivíduo o direito de se autodeterminar, exceto se sobrevir alguma doença mental. A aplicação do princípio da igualdade no direito de família, não se preocupa apenas com a aplicação da isonomia formal, mas também se empenha na relação solidária de amor e afeto por parte dos seus integrantes.

$O$ referido princípio é dividido em duas vertentes, a igualdade formal, que é a isonomia decorrente da lei, vendando qualquer tipo de privilégio e a igualdade material. A material ou substancial, como também conhecida, é a concretude da isonomia formal, busca de fato atingir a previsão da lei, com meios suficientes para tornar os menos privilegiados a usufruir das mesmas oportunidades, ou seja, tratar os iguais igualmente e os desiguais na medida das suas desigualdades. Bulos (2014) compreende que o princípio da isonomia, obsta o legislador a criar normas que impulsionem a desequiparação dos cidadãos de forma antijurídica, violando o exposto na Constituição Federal.

\subsection{A AFETIVIDADE E SOLIDARIEDADE NAS RELAÇÕES CONJUGAIS SEPTUAGENÁRIAS}

A família sofreu consideráveis alterações em sua composição antes mesmo da entrada em vigor da atual Constituição Federal, desde a natureza até a sua função. Ao longo do século XX a urbanização acelerada e a emancipação política contribuíram de forma relevante para o fim da família patriarcal, atribuindo a afetividade e solidariedade como fator nuclear e definidor da união familiar. Com a promulgação da Constituição de 1988, a incidência dos novos valores e conceitos de família, afastou o modelo patriarcal do Código de Beviláqua.

A afetividade, de forma geral, já vem enraizada de forma natural desde o nascimento, com os genitores e o recém-nascido e vice-versa. Perdura-se por toda a existência em vários ciclos da vida, desde a infância, adolescência, adulto, encerrando com a chegada da velhice, sendo assim, a afetividade está presente em todas as fases da vida humana.

Por isso, houve a necessidade dessas relações entre pessoas de serem regulamentadas pelo ordenamento jurídico, atribuindo ao direito de família essa competência. Cabe enfatizar que o afeto, conforme os ensinamentos de Madaleno (2016), é a mola propulsora dos laços familiares para dar sentido e dignidade à existência humana, portanto, muitas das vezes esse vínculo afetivo sobrepõe os laços consanguíneos.

Isto posto, em decorrência da afeição entre os indivíduos, estabelece a vontade de constituir família fundado em um lar e ter uma vida em comum. Atualmente, nos diversos conceitos de família a 
prevalência dos laços afetivos sobrepõe os interesses patrimoniais, mesmo que o patrimônio sempre esteja ligado a relação, não sendo diferente nas relações conjugais septuagenárias. É importante destacar que a Constituição Federal tutela implicitamente a afetividade como repersonalização, compreendendo que a pessoa está acima do patrimônio por não ter um preço, mas sim uma dignidade.

Desta maneira, Pereira (2011), ensina que os alicerces da família não estão mais na submissão econômica, mas sim no companheirismo, cumplicidade, solidariedade mútua e no afeto entre os seus membros. Assim sendo, é imprescindível a solidariedade como elemento conformador dos direitos subjetivos na contemporaneidade, esse princípio encontra-se implicitamente no artigo 230 da Constituição Federal de 1988, visando proteger os mais vulneráveis, especificamente os idosos. Madaleno (2016) conceituou a solidariedade como o princípio oxigênio de todas as relações afetivas, pois o vínculo somente se subsiste se promover um ambiente de cooperação, compreensão e reciprocidade.

Além disso, contrapondo o fato que nessa fase da vida onde os septuagenários não têm mais o fervor da juvenilidade, o que não se pode omitir é que "a família deixou de ser casamento, sexo e reprodução", para ser muito mais amplo do que esses quesitos, embora importantes, fato é que com o passar dos tempos houve uma evolução, priorizando o respeito e a afetividade nessas relações, tanto nas septuagenárias, como nas demais.

O Ministro Marco Aurélio (2011, p. 10), corroborando com esse entendimento, em seu voto, compactua desse mesmo pensar a respeito desse assunto, que diz:

Revela-se, então, a modificação paradigmática no direito de família. Este passa a ser o direito "das famílias", isto é, das famílias plurais, e não somente da família matrimonial, resultante do casamento. Em detrimento do patrimônio, elegeram-se o amor, o carinho e a afetividade entre os membros como elementos centrais de caracterização da entidade familiar.

Quando o legislador impõe um determinado regime de bens aos maiores de 70 (setenta) anos, ele está afrontando não somente o princípio da afetividade, mas como também o da dignidade de cada consorte no que diz respeito ao direito à liberdade e igualdade quando afasta o afeto existente naquela relação conjugal. A jurisprudência tem se manifestado em sentido contrário à disposição legal, demonstrando a valorização do afeto como elemento essencial no estabelecimento do convívio familiar, superando as vezes o vínculo biológico, podendo ser confirmado por várias decisões reconhecendo a paternidade socioafetiva.

A imposição da separação obrigatória de bens para os septuagenários sob a justificativa de protegê-los, pressupõe que todo relacionamento em que o idoso seja parte, se funda em interesses exclusivamente patrimoniais, sendo afastado categoricamente o afeto entre eles. Presumindo que ao atingir determinada faixa etária as pessoas se tornam imunes aos sentimentos afetivos, como se a experiência adquirida ao longo de anos as tornasse incapazes de constituir um matrimônio baseado no respeito, ânimo de comunhão de vida e no afeto. Acontece, que a norma prevista no artigo 1641, inciso II do Código Civil de 2002, deixa de tutelar em primeiro plano a pessoa humana e os seus sentimentos, supervalorizando o patrimônio do idoso. 


\section{DA MITIGAÇÃO DA LIBERDADE DE ESCOLHA DO REGIME DE BENS PARA O MAIOR DE 70 ANOS}

A legislação civil impõe aos idosos maiores de 70 anos que estejam na iminência de contrair matrimônio, que seja compactuado por meio do regime de separação obrigatória de bens com previsão legal no art. 1641, inciso II, do Código Civil de 2002. Contudo, o alcance dos efeitos da norma jurídica ultrapassa o vínculo matrimonial e estende-se ao instituto da união estável.

O instituto da união estável é reconhecido pela Constituição Federal de 1988, em seu art. 226, $\S 3^{\circ}$, in verbis:

Art. 226. A família, base da sociedade, tem especial proteção do Estado.

[...]

$\S 3^{\circ}$ Para efeito da proteção do Estado, é reconhecida a união estável entre o homem e a mulher como entidade familiar, devendo a lei facilitar sua conversão em casamento.

Posteriormente reproduzida e regulamentada pelo Código Civil de 2002, no art. 1.723 caput: “É reconhecida como entidade familiar a união estável entre o homem e a mulher, configurada na convivência pública, contínua e duradoura e estabelecida com o objetivo de constituição de família"

Cabe ressaltar que a redação está desatualizada, tendo em vista o reconhecimento da união estável nas relações homoafetivas por meio do julgamento da ADI 4277 em 5 de maio de 2011. Ou seja, os conviventes em união estável passaram a receber proteção semelhantes às definidas pelo casamento e são regidos pela comunhão parcial de bens.

Todavia, quando se trata de união estável em que um dos conviventes ou ambos já estejam na faixa etária acima dos 70 anos, gera uma grande discussão doutrinária se é aplicável ou não a separação legal. Dias (2011) destaca de que a separação obrigatória de bens para os septuagenários não se estende à união estável, pois não há previsão legal para isso, desta maneira seria mais vantajoso manter uma relação informal em que estabelece, em regra, a comunhão parcial de bens.

Tartuce (2014) também comunga desse entendimento, discorre que em nenhum dos casos previstos no art. 1641 do CC/02 abrange o instituto da união estável e por ser uma norma restritiva da autonomia privada não se admite uma interpretação extensiva ou por analogia. Assevera ainda, que a norma gera restrição apenas para o casamento, sendo que não existe hierarquia entre as categorias familiares, pois devem ser tratados de maneiras distintas quanto aos direitos e deveres.

Existe, contrapondo o parágrafo anterior, outra corrente que repudia esse entendimento, por compreender que nas duas situações (casamento e união estável) devem ser interpretados de maneira igualitária. Ou seja, impõe o regime de separação obrigatória na união estável ou não se aplica para o casamento a restrição ao direito de livre escolha do regime patrimonial (CANUTO apud TARTUCE, 2014).

Sendo assim, o STJ no julgamento do REsp 1689152/SC, firmou entendimento de que as disposições referentes ao regime de separação obrigatória são aplicáveis à união estável daqueles que passarem a viver em união estável após os setenta anos de idade. Ou seja, tanto no casamento quanto na relação informal da união estável se aplicará os mesmos efeitos do art. 1641, inciso II, do CC/02. 
Contudo, há uma "exceção" em que a obrigatoriedade não será aplicada, somente quando o casal já vivia em união estável antes de haver restrições legais à escolha do regime de bens, pois não faz sentido optar por um regime mais gravoso se antes poderiam optar por quaisquer regimes previstos na legislação brasileira sem qualquer interferência legal.

Posto isto, podemos verificar o seguinte, que a liberdade prevista nos demais regimes patrimoniais: comunhão universal, parcial, participação final nos aquestos e separação convencional é mitigada na separação obrigatória de bens, ou seja, quando envolve idosos iguais ou maiores de 70 anos a sua autonomia é restringida.

\subsection{CORRENTES DOUTRINÁRIAS A FAVOR E CONTRÁRIA A DISPOSIÇÃO LEGAL}

Antes de abordar de fato os posicionamentos das correntes doutrinárias, cabe mencionar que o Código Civil de 1916 atendia aos anseios e interesses das classes dominantes da época, que tinham uma base burocrática e organizacional cujo objetivo era de adquirir patrimônio. Destarte, estabelece como objetivo maior presente no código o da proteção ao patrimônio.

Segundo Fachin (2013, p. 317):

No Código Civil cunhou-se um viés de conservação das relações de ordem patrimonial, contratual e familiar, fiel ao contexto e à história dos valores dominantes. [...] Os valores que inspiravam a regulação jurídica do patrimônio e que foram abrigados pelo código não raro serviram como escudo a essas transformações.

No Código revogado, o pai era considerado o chefe da família, no qual os demais integrantes eram subordinados a sua autoridade, essa supremacia pode ser observada em vários dispositivos do Código de Beviláqua. No art. 240, a mulher tinha a função de colaboração do marido no exercício dos encargos da família, cumprindo a ela velar pela direção material e moral, enquanto o marido era incumbido de chefiar a sociedade conjugal (art. 233).

Para o menor de 21 anos casar era necessário o consentimento dos genitores, mas na divergência entre eles, prevaleceria a vontade paterna, configurando a posição "privilegiada" da figura masculina na sociedade conjugal. Segundo Eduardo Silva (2002, p. 450), “a família do Código Civil de 1916 era uma família transpessoal, hierarquizada e patriarcal".

Por fim, segundo o art. $6^{\circ}$, inciso II do mesmo diploma, a figura feminina era considerada relativamente incapaz, verificando-se que o objetivo do legislador era deixar a mulher como subordinada ao comando masculino, seja do esposo, pai, e até do irmão na falta destes.

Essa concepção deu origem a corrente patrimonialista, defensores da constitucionalidade do artigo 1.641, II, do CC/02 entendem como restrição eminentemente protetiva em que se objetiva obstar a realização de casamento exclusivamente por interesse econômico. Manifestam ser cabível a intervenção do Estado nessa questão, pois se trata de ordem preventiva, visando à garantia da paz familiar ao preservar que o patrimônio adquirido por meio de uma história de lutas e sacrifícios da família não seja dissolvido. 
Tem-se o entendimento de que as pessoas com idade superior a 70 anos são tidas como mais frágeis e, portanto, necessitam de uma proteção maior do Estado principalmente no que diz respeito a terceiros que visam a auferir alguma vantagem em relação ao patrimônio dos idosos. Com essa norma, os idosos não se tornarão presas mais fáceis para o enriquecimento dos que têm interesse em seus patrimônios.

Nesse sentido, necessário se faz mencionar o entendimento do doutrinador Monteiro (2012), que afirma que a separação obrigatória de bens não afronta o princípio da liberdade, pois ele não é um princípio absoluto, encontrando impedimentos no próprio ordenamento jurídico. Completa ainda, aduzindo que o Direito de Família não pode acolher que um casamento seja exercido com fins meramente financeiros em detrimento do cônjuge mais velho e de seus familiares.

Venosa (2010), perfilha pensamento semelhante, ao asseverar que nessa fase da vida, quando um ou ambos os nubentes estão consolidados financeiramente, quando não se tem mais o fervor da juvenilidade, o patrimônio deve ser afastado categoricamente. A visão é separar o interesse patrimonial do casamento de uma pessoa jovem com alguém bem mais avançado em idade.

Portanto, para esses doutrinadores do Direito, a aplicação do artigo é constitucional e não viola qualquer proteção garantida pela Carta Magna e o Estatuto do Idoso. Sendo assim, não há qualquer discriminação ou preconceito em relação aos septuagenários, tendo apenas uma segurança garantida que caso o matrimônio não seja como o planejado, os bens estarão protegidos do interesseiro.

Já para a corrente doutrinária personalista, que interpretam à luz dos princípios vetores da Constituição Federal que logo em seu artigo $1^{\circ}$, inciso III, prevê a dignidade da pessoa humana como fundamento do Estado Democrático de Direito, bem como no artigo $5^{\circ}$ diz que todos são iguais perante a lei, sem distinção de qualquer natureza, em direitos e obrigações, entendem ser completamente preconceituoso e discriminatório ao idoso, tornando-o "relativamente incapaz", sendo condenado pela lei sem o devido processo legal e sem o direito de defesa. Se no direito civil prevalece a autonomia privada sob a ingerência estatal, assim acontecerá no direito das famílias, pois é parte integrante e inseparável do direito civil privado.

Nesse sentido personalista, compreende Dias (2015) que o dispositivo se trata de uma espécie de sanção, distante de ser uma norma protetiva, afrontando o Estatuto do Idoso e limitando à vontade em razão da idade. Presume-se a absoluta demência do idoso, sem buscar qualquer meio probatório, retirando a liberdade e capacidade de escolher em qual regime de bens quer se casar. Dias ainda se manifesta sobre a incoerência da norma, levando-se em conta que os acima de 70 anos podem exercer cargos de maiores importância na nação brasileira, como por exemplo, o de chefe do poder executivo federal, presidentes das casas legislativas, ministros das cortes superiores do judiciário e, no entanto, não poderiam exercer o direito de livremente escolher o seu regime de casamento.

A corroborar o exposto acima, Braga (2011) manifesta a total ilegalidade e inconstitucionalidade do artigo 1.641, II, CC/02, uma vez que, o maior de 70 anos não está inserido em nenhuma hipótese de incapacidade prevista nos artigos $3^{\circ}$ e $4^{\circ}$ do atual Código Civil, contrariando o artigo $1^{\circ}$ que presume a capacidade como regra. Desta feita, toda e qualquer interferência do Estado nas famílias somente é justificável se possuir como base a defesa dos interesses e da pessoa física dos próprios indivíduos, principalmente daqueles que, por motivo permanente ou transitório, não puderem se defender ou representarem a si mesmos. 
Ao trazer os argumentos protecionistas já mencionados usados pelo legislador do Código Civil, de que a intervenção do Estado se tratou de ordem preventiva, visando à garantia da paz familiar ao preservar que o patrimônio adquirido por meio de uma história de lutas e sacríficos da família não seja dissolvido, pois bem, a medida imposta não logrou o êxito pleno, tendo em vista que, o cônjuge mais velho poderá contemplar o cônjuge mais jovem pelo testamento da parte disponível, ou por meio de doação.

O Superior Tribunal de Justiça vem admitindo em sua jurisprudência por meio do Resp 471958/ RS, que a doação entre cônjuges submetidos ao regime de separação obrigatória de bens é válida, com o argumento de que não há norma expressa, vedando ou permitindo o ato de liberalidade.

Processual civil. Recurso especial. Ação de conhecimento sob o rito ordinário. Casamento. Regime da separação legal de bens. Cônjuge com idade superior a sessenta anos. Doações realizadas por ele ao outro cônjuge na constância do matrimônio. Validade. - São válidas as doações promovidas, na constância do casamento, por cônjuges que contraíram matrimônio pelo regime da separação legal de bens, por três motivos: (i) o CC/16 não as veda, fazendo-no apenas com relação às doações antenupciais; (ii) o fundamento que justifica a restrição aos atos praticados por homens maiores de sessenta anos ou mulheres maiores que cinqüenta, presente à época em que promulgado o $C C / 16$, não mais se justificam nos dias de hoje, de modo que a manutenção de tais restrições representam ofensa ao princípio da dignidade da pessoa humana; (iii) nenhuma restrição seria imposta pela lei às referidas doações caso o doador não tivesse se casado com a donatária, de modo que o Código Civil, sob o pretexto de proteger o patrimônio dos cônjuges, acaba fomentando a união estável em detrimento do casamento, em ofensa ao art. 226, $\S 3^{\circ}$, da Constituição Federal. Recurso especial não conhecido.

Além disso, a ministra Nancy Andrighi, respaldou o seu voto no sentido de que não haveria restrições impostas pela lei referida as doações, se o doador não fosse cônjuge da beneficiária. Logo, se não fossem casados seriam permitidas as doações, então não há justificativas para impedir a dádiva na relação conjugal.

0 ato de dispor do patrimônio para o cônjuge ou qualquer pessoa que seja, essa liberalidade encontra-se contida no princípio da autonomia da vontade, ressalvando a diferenciação existente entre a autonomia da vontade e a autonomia privada. No primeiro caso, a autonomia da vontade é a liberdade de se autogovernar e tomar decisões, possuindo um caráter subjetivo, psicológico, tendo a possibilidade de efetuar negócios jurídicos, com quem irá contratar e como será o contrato.

Já no segundo caso, a autonomia privada está ligada a norma, onde o cidadão também tem o poder de contratar, estabelecer regras, desde que estejam em conformidade com ordenamento jurídico, tendo um caráter mais objetivo, intervindo o Estado na relação familiar. Na prática, a intervenção do Estado no âmbito das relações familiares, acaba restringindo a autonomia da vontade de forma evasiva, privando os sujeitos de se autodeterminarem o modo de vida, como é o caso do regime de separação de bens para os septuagenários.

Quando o Estado pretende proteger o patrimônio dos herdeiros, há que se falar que no artigo 426 do Código Civil, expressamente prevê que não pode ser objeto de contrato a herança de pessoa viva, 
entende-se que enquanto o titular do patrimônio, o maior de 70 anos no caso em tela, estiver vivo, ele poderá administrar os seus bens como bem lhe aprouver, restando claro que os herdeiros tem apenas um direito eventual a sucessão, ressalvando a hipótese de o detentor do patrimônio dispor dos seus bens em vida aos herdeiros por vontade própria.

Em relação à proteção da herança em favor daqueles que a herdarão, Tartuce e Simão (2013, p. 146) afirmam que "a justificativa de proteção patrimonial dos herdeiros não é plausível. Ora, se esses querem juntar um bom patrimônio, que o façam diante do seu trabalho. Ser herdeiro não é profissão."

O legislador foi omisso nos casos em que o idoso não tem herdeiros para deixar o seu patrimônio após a morte, por meio do direito sucessório, também nos casos em que ambos os nubentes se encontram na mesma situação etária de 70 anos ou mais, estão em igualdade, nessa situação não se pode presumir necessariamente o interesse um do outro. Em ambos os casos, mesmo assim será imposto o regime do artigo 1.641, II, do Código Civil. Nas situações mencionadas, não haverá os supostos “golpes do baú" como o legislador visou prevenir, mais justo seria eles exercerem a autonomia de escolher o regime patrimonial.

\subsection{APLICABILIDADE DA SÚMULA 377 DO STF NA SEPARAÇÃO OBRIGATÓRIA DE BENS}

A não comunicação do patrimônio até mesmo adquiridos na constância do casamento, levou o Supremo Tribunal Federal (STF) no ano de 1964, a criar a súmula 377, pois, é nítido que a adoção do regime de separação obrigatória de bens poderá gerar um enriquecimento ilícito, tendo em vista que o outro cônjuge poderá contribuir de alguma forma (não necessariamente financeiro) para o aumento patrimonial e não desfrutará em caso de morte ou dissolução da união conjugal. Sendo assim, comunicam-se os bens adquiridos na constância do casamento. "Súmula 377 do STF - No regime de separação legal de bens, comunicam-se os adquiridos na constância do casamento".

Com a edição da Súmula surgiram três correntes principais quanto à aplicabilidade, os que defendiam a sua aplicação em vedação ao enriquecimento sem causa e com a edição do código de 2002 passaram a sustentar-se na vedação ao enriquecimento ilícito, outra corrente entende que com a edição do Código Civil de Reale, a súmula não deve ser aplicada diante da revogação do diploma legal anterior.

A terceira corrente defende a aplicabilidade, desde que comprovado o esforço comum. A Súmula poderá ser interpretada de duas formas, os que interpretam que a contribuição do cônjuge é presumida e os que entendem que o esforço comum deverá ser comprovado para que haja a meação.

Tartuce (2017, p. 97), por sua vez, acredita por diversos motivos que é necessário esforço comum para a aplicação da Súmula 377, in verbis:

Com o devido respeito, o presente autor pensa de forma diferente. Primeiro, porque a falta da prova do esforço comum transforma o regime da separação de bens em uma comunhão parcial, o que não parece ter sido o objetivo da sumular. Segundo, diante da vedação do enriquecimento sem causa, constante do art. 884 do Código Civil, eis que a comunicação automática ocorreria sem qualquer razão plausível, em decorrência do mero casamento. Terceiro, porque o presente autor tem suas ressalvas quanto à eficiência atual do regime 
da comunhão parcial de bens. Quarto, pois o melhor caminho para o nosso Direito é extinguir definitivamente a separação legal e não transformá-la em outro regime, o que seria uma solução temporária.

A razão principal que levou o Supremo a editar a súmula foi a divergência que ocorria quanto a aplicabilidade do previsto no caput do art. 259 do diploma de 1916, que embora não fosse o regime da comunhão de bens, prevaleceria no silêncio do contrato, os princípios dela, quanto a comunicação dos adquiridos na constância do casamento. Ou seja, em situações em que o pacto nupcial não excluísse expressamente, apesar de estabelecido o regime de separação, não se aplicava a incomunicabilidade dos bens na constância do matrimônio, adquiridos onerosamente.

Esclareceu a sua extensão ao regime obrigatório, no entanto, ao longo desses anos foi instaurado um extenso debate sobre a necessidade ou não da comprovação do esforço comum para a divisão dos aquestos, o Superior Tribunal de Justiça (STJ), por meio da segunda Seção, uniformizou o seu entendimento diante da divergência que ocorria entre a terceira e quarta Turma do colegiado, no sentido da necessidade da comprovação do esforço comum, pois é a que mais se adequa ao estabelecido pelo regime de separação legal.

0 mesmo entendimento do STJ tem sido seguido por alguns tribunais do Brasil, a exemplo do Egrégio Tribunal de Justiça de Santa Catarina (TJSC) no julgamento da Apelação Cível $n^{\circ}$ 000887408.2013.8.24.0023, em que acordaram os Desembargadores na ação de reconhecimento de fato post mortem, pelo desprovimento, frente à ausência de provas para comprovação do esforço comum para a divisão dos bens adquiridos na constância da união, com efeitos da imposição do regime mitigado pela súmula 377 do STF.

De forma oposta ao entendimento acima exposto, o Egrégio Tribunal de Justiça do Rio Grande do Sul (TJRS), no julgamento da Apelação Cível n 70075804211, os Desembargadores acordaram que a meação do viúvo em casamento celebrado pelo regime de separação obrigatória é presumida, independente de comprovação de contribuição onerosa, por parte do sobrevivente. Apesar do STJ ter uniformizado o seu entendimento, ainda não é questão pacificada entre os demais Tribunais brasileiros.

Há doutrinadores que se posicionam pela revogação da Súmula, a exemplo de Cahali (2004), pelo fato de que o diploma Civil de 2002, não reproduziu o contido no artigo 259 do antigo Código, já que ela se originou daquela previsão e que o regime de separação obrigatória no atual Código passa a ser um regime de efetiva separação patrimonial, excetuando os adquiridos por meio do esforço comum, configurando uma sociedade de fato sobre os bens. Como consequência, o enriquecimento sem causa, tornou-se a principal premissa tanto para os defensores, quanto para os que se manifestam pela revogação da súmula 377 do STF.

Por outro lado, os que defendem a continuidade como Chaves e Rosenvald (2010, p. 250), porquanto "razões de equidade autorizam a prevalência da Súmula", uma vez que a imposição aos nubentes de total incomunicabilidade dos bens não abre espaço para expor a vontade do casal, sendo assim, com a súmula são respeitados os "valores personalíssimos, realçando a proteção das pessoas humanas envolvidas", afastando a injusta imposição estatal no âmbito familiar e interesses privados.

Portanto, depois de analisar alguns princípios constitucionais e normas de relevo, bem como cor- 
rentes doutrinárias a favor e contra a aplicabilidade do artigo 1.641, II, do Código Civil, adiante será apresentado os posicionamentos jurisprudenciais dos tribunais.

\subsection{ANÁLISE JURISPRUDENCIAL ACERCA DA APLICACÃO DO REGIME DE SEPARAÇÃO OBRIGATÓRIA DE BENS PARA OS MAIORES DE 70 ANOS}

Como já demonstrado anteriormente, a doutrina moderna tem entendido pela inconstitucionalidade do dispositivo por infringir os princípios constitucionais da dignidade da pessoa humana, da autonomia e da liberdade. Sendo assim, a jurisprudência se responsabilizou em minimizar os efeitos gerados por este regime diante da suposta inconstitucionalidade, observando-se alguns precedentes judiciais que já permitem aos noivos maiores de 70 anos escolherem qual regime mais the aprouverem.

Os parlamentares, conscientes da atual realidade da sociedade brasileira, bem diferente da sociedade da época da elaboração do Código Civil de 1916, propuseram mudanças legislativas com o objetivo de alterações e possível revogação do dispositivo em análise. Mesmo com tantos avanços em geral, aumento da expectativa de vida, a presença cada vez maior dos idosos no mercado de trabalho, ainda assim não foram suficientes para extinguir o protecionismo exasperado contido no art. 1641, II, do Código Civil de 2002.

Tramitaram desde o início da década passada, no Congresso Nacional, projetos de leis, que buscavam permitir aos septuagenários o direito de escolher o regime de bens. Por exemplo, o Projeto de Lei (PL) 507/2007, de autoria do Deputado Federal Sérgio Barradas Carneiro, renovando os argumentos utilizados na PL 4945/2005, proposto pelo Deputado Federal Antônio Carlos Biscaia por ser atentatório à dignidade dos mais idosos, sendo arquivado em 2011.

Também foi proposta a revogação do aludido dispositivo no Senado Federal, por meio do Senador José Maranhão, ponderando que não há razões científicas que justifiquem que a lei considere os septuagenários como pessoas necessitadas da proteção estatal no sentido de delimitar o seu direito de escolha do regime patrimonial. Longe disso, sustenta o Senador que "tais pessoas aportariam a maturidade de conhecimentos da vida pessoal, familiar e profissional, devendo ser prestigiadas quanto à capacidade de decidir por si mesmas". Concluiu, fazendo uma breve comparação com os próprios colegas de parlamento que analisaram a questão, já que muitos deles são idosos, com a finalidade de adequar a legislação infraconstitucional com os mandamentos constitucionais, pedindo então pela revogação art. 1641, II, do Código Civil de 2002.

O Projeto de Lei mais recente foi o PL 189/2015 de autoria do Deputado Cléber Verde, sustentou o seu posicionamento, afirmando que os legisladores do Código Civil de 2002, ignoraram todo o processo de repersonalização do Direito de Família, sendo arquivado em 31 de outubro de 2019.

Embora o STF não tenha declarado a constitucionalidade ou inconstitucionalidade da separação legal de bens para os septuagenários por meio do controle concentrado de constitucionalidade, os Tribunais Estaduais têm manifestado seus posicionamentos por cada caso concreto, por meio do controle difuso, entendendo como norma violadora dos direitos constitucionais, como da dignidade da pessoa humana, isonomia ou atestando a constitucionalidade do artigo 1641, II, do Código Civil como norma protetora dos direitos do idoso. 
O Conselho da Justiça Federal (CFJ) já discutiu o assunto por meio da primeira Jornada de Direito Civil no Enunciado $n^{0} 125$, defendendo a revogação do dispositivo legal, sob a justificativa de que 0 legislador não levou em consideração o aumento da expectativa de vida do idoso, além de manter o preconceito. Diante disso, essa dicotomia existente na jurisprudência só será finalizada quando houver um posicionamento do Supremo Tribunal Federal sobre a constitucionalidade ou inconstitucionalidade do mandamento, advindo do artigo 1641, inciso II do Código Civil vigente.

\section{CONSIDERAÇÕES FINAIS}

O envelhecimento e a consequente longevidade dos cidadãos brasileiros, vêm despertando cada vez mais a busca por conhecimentos a fim de compreender a nova realidade dos idosos. Não podendo ser diferente no Direito. Especificamente no âmbito do Direito de Família, merece destaque a obrigatoriedade no qual impõe aos septuagenários a somente se casar mediante separação legal de bens, o que estimula o relevo desta pesquisa, tendo em vista o elenco de garantias e direitos fundamentais previstos na Constituição Cidadã de 1988.

A norma edificada exclusivamente na questão etária, sem fundamentos subjetivos e individuais capazes de elaborar um parecer técnico sobre a capacidade do idoso, continua a impulsionar o estudo sobre a violação ou não das garantias constitucionais, emergidas pelos direitos fundamentais e editadas no princípio da dignidade da pessoa humana, no que concerne a privação à liberdade, individualidade e à autonomia da vontade.

$\mathrm{Na}$ concepção patrimonialista, vislumbrou-se o aspecto protetor em favor do idoso, como pessoa vulnerável na sociedade e que necessita de uma proteção estatal para que os seus bens não sejam lesados por consequência de um casamento exclusivamente por interesses econômicos. Com isso, os idosos não se tornarão presas mais fáceis para o enriquecimento dos que têm interesse em seus patrimônios.

Todavia, concordar com esse entendimento é o mesmo que dizer que os idosos não tem mais capacidade de ter uma relação de afeto com qualquer pessoa que seja, além de presumir uma demência sem nenhum meio probatório, ou seja, ser condenado legalmente sem direito a defesa e contraditório.

Já para a concepção personalista, defensores da revogação do dispositivo, fundamentam-se no princípio da dignidade da pessoa humana, no estado democrático de direito, entendem ser uma norma discriminatória e preconceituosa. Destaca-se que a Constituição Federal de 1988 tutela implicitamente a afetividade como repersonalização, compreendendo que a pessoa está acima do patrimônio por não ter um preço, mas sim uma dignidade.

A relevância social do objeto de estudo, no que diz respeito a capacidade do idoso em exercer todos os aspectos da vida com qualidade, tanto no mercado de trabalho quanto na parte sentimental e afetiva, longevidade e uma voz mais ativa perante a sociedade, deixa para trás a preconcepção de idosos incapazes e dependentes.

De acordo e com base nos estudos analisados nesta pesquisa, considera-se que de fato a norma prevista no art. 1641, inciso II do Código Civil de 2002, no qual estabelece que os maiores de 70 anos 
somente poderão contrair matrimônio sob o regime de separação obrigatória de bens, tem um caráter protetivo exacerbado, ocasionando uma discriminação ao idoso, contrariando direitos estabelecidos na Constituição Federal de 1988 e na legislação infraconstitucional.

Assim, o Estado tem a obrigação e precisa proteger os mais vulneráveis e hipossuficientes, desde que o faça, analisando cada caso concreto, de forma que a imposição legal seja considerada uma exceção no ordenamento jurídico e não como regra. Assim, diante da relevância social e moral no que diz respeito ao direito de liberdade de escolha do regime de bens para os septuagenários, entende-se pela necessidade da revogação do dispositivo.

O Código Civil deve ser interpretado conforme as diretrizes e mandamentos previstos na Constituição e não a Constituição segundo o Código. Por isso, não compete ao Direito restringir as relações que evolvam a afetividade, mas sim, preocupar-se com a valorização do ser humano em busca da felicidade. O ser humano é um ser social e sempre buscará alguém que possa compartilhar momentos da sua vida.

Diante disso, sugere-se uma forma de minimizar os efeitos da imposição estatal nas relações septuagenárias, garantindo o direito à liberdade de escolher qual o tipo de administração exercerá sobre o seu patrimônio. Uma medida mais branda que poderá ser adotada é no caso de não formulação do pacto antenupcial, ou seja, na omissão dos nubentes, ser aplicado o regime de separação legal de bens, mas garantindo o direito de escolha, podendo modificar o regime a qualquer tempo por meio de processo judicial, apurando a procedência das razões invocadas.

Por todos os fundamentos apresentados, considera-se que a norma contida no art. 1641, inciso II do Código Civil de 2002, aplicando a separação legal de bens aos idosos maiores de 70 anos tem de fato um caráter discriminatório e preconceituoso, devendo ser revogada totalmente para possibilitar aos nubentes septuagenários escolham livremente o regime de bens que norteará os aspectos patrimoniais do casamento.

\section{REFERÊNCIAS}

ANCIÃOS transmitem cultura indígena. 2002. Disponível em: http://www.comciencia.br/ dossies-1-72/reportagens/envelhecimento/texto/env06.htm. Acesso em: 13 set. 2020.

BRAGA, Pérola Melissa Vianna. Curso de direito do idoso. São Paulo: Atlas, 2011.

BRASIL. Enunciados da I Jornada de Direito Cível. Disponível em: https://www.cjf.jus.br/cjf/ CEJCoedi/jornadascej/Jornada\%20de\%20Direito\%20Civil\%201.pdf/view. Acesso em: 9 nov. 2020.

BRASIL. STF - Supremo Tribunal Federal. Súmula no 377 de 03/04/1964 - DJ de 8/5/1964, p. 1237; DJ de 11/5/1964, p. 1253; DJ de 12/5/1964. Disponível em: http://www.stf.jus.br/portal/ jurisprudencia/menuSumarioSumulas.asp?sumula=4022. Acesso em: 18 nov. 2020. 
BRASIL. STF - Supremo Tribunal Federal. Ação Direta de Inconstitucionalidade, $\mathbf{n}^{0}$ 4.277.

Disponível em: www.stf.jus.br/portal/geral/verPdfPaginado.asp?id=400547\&tipo=TP\&descricao=ADI \%2F4277. Acesso em: 13 set. 2020.

BRASIL. STJ - Superior Tribunal de Justiça. Recurso Especial 1689152 SC (2011/0235045-8). Quarta Turma. Relator Ministro Luis Felipe Salomão. 24 de outubro de 2020. Disponível em: https:// processo.stj.jus.br/processo/revista/documento/mediado/?componente=ATC\&sequencial=7852178 8\&num_registro=201102350458\&data=20171122\&tipo=5\&formato=PDF. Acesso em: 20 nov. 2020.

BRASIL. STJ - Superior Tribunal de Justiça. REsp 471958/RS, Rel. Min. Nancy Andrighi, Terceira Turma, julgado em 18/12/2008, DJe de 18/02/2009. Disponível em http://www.stj.jus.br/SCON/ jurisprudencia/toc.jsp?tipo_visualizacao $=$ null\&livre=doa\%E7\%E30+e+c\%F4njuge+e+sexagen $\% E 1 \mathrm{r}$ io\&b=ACOR. Acesso em: 20 nov. 2020.

BRASIL. Tribunal de Justiça do Estado de Sergipe. Incidente de inconstitucionalidade.

2010107802. Tribunal Pleno. Relator Des. José dos Anjos, Sergipe 17 nov. 2010. Disponível em: http://tjse.jusbrasil.com.br/jurisprudencia/18120797/incidente-de-inconstitucionalidade-iin2010107802-se-tjse. Acesso em: 6 nov. 2020.

BRASIL. Tribunal de Justiça do Estado de Sergipe. AC 201300202403. $2^{\text {a }}$ Câmara Cível. Relator Des. José dos Anjos, julgado em 26/03/2014. Disponível em: https://tj-se.jusbrasil. com.br/jurisprudencia/662531436/apelacao-civel-ac-64914820038250001/inteiro-teor662531441?ref=feed. Acesso em: 20 nov. 2020.

BRASIL. Tribunal de Justiça do Estado do Paraná. Agravo de Instrumento no 993.733-1. 11ª Câmara Cível. Relatora Desa. Vilna Régia Ramos Rezende, julgado em 11/12/2013. Disponível em: https:// tj-pr.jusbrasil.com.br/jurisprudencia/24817860/acao-civil-de-improbidade-administrativa-9937331pr-993733-1-acordao-tjpr/inteiro-teor-24817861. Acesso em: 21 nov. 2020.

BRASIL. Tribunal de Justiça do Rio Grande do Sul. AC 70075804211/RS, Relator. Des. Rui Portanova, oitava Câmara Cível, julgado em 22/03/2018, Dje de 26/03/2018. Disponível em: https:// tj-rs.jusbrasil.com.br/jurisprudencia/560294912/apelacao-civel-ac-70075804211-rs/inteiroteor-560294922. Acesso em: 19 nov. 2020

BULOS. Uadi Lammêgo. Curso de direito constitucional. 5. ed. São Paulo: Saraiva, 2014.

CAHALI, Francisco José. A súmula n. 377 e o novo código civil e a mutabilidade do regime de bens. In: Homenagem ao Professor Silvio Rodrigues. Revista do Advogado, São Paulo, ano XXIV, jun. 2004, n. 76, 2004. 
CALDERÓN. R. Princípio da afetividade no direito de família. 2. ed. Rio de Janeiro: Forense, 2017.

CUNHA PEREIRA, Rodrigo da. Princípios fundamentais norteadores do direito de família. São Paulo. Saraiva, 2011.

DIAS, Maria Berenice. 0 novo código civil. Disponível em: www.buscalegis.ufsc.br/revistas/files/ anexos/7863-7862-1-PB.htm. Acesso em: 24 set. 2020.

DIAS, Maria Berenice. Manual de direito das famílias. 10. ed. rev., atual. e ampl. Sào Paulo: Editora Revista dos Tribunais, 2015.

DIAS, Maria Berenice. Manual de direito das famílias. 6. ed. São Paulo: Editora Revista dos Tribunais, 2011.

FACHIN, Luiz Edson. Comentários ao novo código civil: do direito de família; do direito pessoal; das relações de parentesco. v.18. Coordenador Sálvio de Figueiredo Teixeira. Rio de Janeiro: Forense, 2003.

FARIAS, Cristiano Chaves de; ROSENVALD, Nelson. Direito das famílias. 2. ed. Rio de Janeiro: Ed. Lumen Juris, 2010.

GONÇALVES, Carlos Roberto. Direito civil brasileiro - volume 6: Direito de Família. 9. ed. São Paulo: Editora Saraiva, 2012.

INDALENCIO, Maristela. Estatuto do idoso e direitos fundamentais: fundamentos da proteção da pessoa idosa no ordenamento jurídico brasileiro. Itajaí-SC: Univali, 2007.

LÔBO, Paulo. Direito civil: famílias. 7. ed. São Paulo: Saraiva, 2017.

MADALENO, Rolf. Direito de família. 8. ed., rev., atual. e ampl. Rio de Janeiro, 2018.

MADALENO, Rolf. Curso de direito de família. 4. ed. 2016.

MASC, Silvia. O olhar ao idoso no Japão e na China. 2013. Disponível em: http://www.ufjf.br/ ladem/2013/06/28/o-olhar-ao-idoso-no-japao-e-na-china-por-silvia-masc/. Acesso em: 13 set. 2020.

MELO, Ana Cristina Soares; MELO, Cláudia Ferreira. Grupos sociais: instrumento na manutenção da saúde do idoso? Mais 60 estudos sobre envelhecimento, v. 25, n. 61. São Paulo: Sesc São Paulo, julho 2014. Disponível em: https://www.sescsp.org.br/files/edicao_revista/4744d5f9-3c12-44ec82e3-c9a847474c80.pdf. Acesso em: 13 set. 2020. 
MONTEIRO, Washington de Barros; SILVA, Regina Beatriz Tavares da. Curso de direito civil: direito de família. V. 2. 42. ed. São Paulo: Saraiva, 2012.

NADER, P. Curso de direito civil: direito de família. 7. ed. Rio de Janeiro: Forense, 2016.

OKUMA, Silene Sumire, $\mathbf{O}$ idoso e a atividade física: fundamentos e pesquisa. Campinas, Papirus, 2004.

SANTANA, Maya. Filhos que dominam e exploram financeiramente pais idosos. 2019. Disponível em: https://www.50emais.com.br/41815-2/. Acesso em: 13 set. 2020.

SILVA, Eduardo. A dignidade da pessoa humana e a comunhão plena de vida: o direito de família entre a Constituição e o Código Civil. In: MARTINS-COSTA, Judith. A reconstrução do direito privado: reflexos dos princípios, diretrizes e direitos fundamentais constitucionais no direito privado. São Paulo: Revista dos Tribunais, 2002. p. 450-451.

TARTUCE, Flávio. Direito civil. Volume 5: direito de família. 12. ed. Rio de Janeiro: Editora Forense, 2017.

TARTUCE, Flávio. Direito civil, v. 5: direito de família. 9. ed. rev., atual. e ampl. Rio de Janeiro: Forense; São Paulo: MÉTODO, 2014.

TARTUCE, Flávio; SIMÃO, José Fernando. Direito civil: direito de família. 8. ed. Rio de Janeiro: Método, 2013.

VENOSA, Sílvio de Salvo. Direito civil: direito de família. V. 6. 14. ed. São Paulo: Atlas, 2014.

VENOSA, Sílvio de Salvo. Direito civil: direito de família. 10. ed. São Paulo: Atlas, 2010.

WAQUIM, Bruna Barbieri; CARVALHO, Márcia Haydeé Porto de. A terceira idade e a restrição legal à livre escolha do regime de bens: uma questão de direitos fundamentais. Revista de Direito Constitucional e Internacional, v. 90, p. 161-187, jan./mar. 2015. 
1 Mestre em Direito pelo Programa de Direito Econômico e Socioambiental - PUCPR; Doutoranda em Direito pela linha de pesquisa Direitos Fundamentais e Novos Direitos pela Sociedade Superior Estácio de Sá (RJ); Especialista em Direito Processual pela Universidade Federal de Sergipe; Advogada, Conselheira Seccional da Ordem dos Advogados do Brasil (SE); Presidente da Comissão dos Direitos da Criança e do Adolescente da OAB/SE; Presidente Estadual do Instituto Brasileiro de Direito de Família - IBDFAM/SE; Professora do Curso de Direito da Universidade Tiradentes (SE) e da Faculdade Pio Décimo e membro do Núcleo Docente Estruturante - NDE. E-mail: acacialelis@gmail.com.br

2 Bacharel em Direito da Faculdade Pio Décimo.

E-mail: gabrieloliveirasoares@live.com

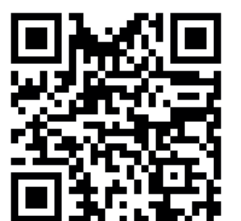

A autenticidade desse artigo pode ser conferida no site https://periodicos. set.edu.br

\section{(2) (1) (-)}

Este artigo é licenciado na modalidade acesso abertosob a Atribuição-Compartilhalgual CC BY-SA

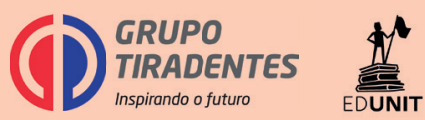

